Acta Crystallographica Section E

Structure Reports

Online

ISSN 1600-5368

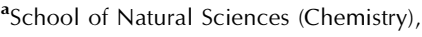
Newcastle University, Newcastle upon Tyne NE1 7RU, England, and ${ }^{\mathbf{b}}$ Cambridge Crystallographic Data Centre, 12 Union Road, Cambridge CB2 1EZ, England

\section{Structure Reports Online: major changes in response to a huge success}

Last year's editorial described a new format for the PDF version of articles published in Section E of Acta Crystallographica, due for introduction in March 2007. We are pleased that the transition to this new format from the previous one went very smoothly. At the same time, enhanced HTML and PDF supplements became available, providing full details of submitted structural results in a convenient and attractive form. Overall the change has led to a significantly shorter average length for published articles (1.6 instead of 2.5 pages), a small reduction in the average time from submission to publication (from 0.9 to 0.8 months), and a reduction in the average cost of publication of articles. This last factor was one reason for changing the publication format, following a decision by the IUCr Executive Committee to move the journal's operation and distribution from a subscription basis to an open-access model - the first journal of the IUCr to take this step. The intention was to keep the open-access fee, charged to authors, as low as possible. This has been achieved successfully, with a standard fee of only USD 150, when the open-access charges of most scientific journals for full research papers are in the thousands of dollars. The resulting combination of free access to the journal for all readers, a low charge to authors, a range of generous discounts from the standard fee and the high quality of the publication package provided by the journal is proving very attractive, and the drying up of submissions predicted by some observers following this major change has not occurred: over 100 papers were submitted in the first three weeks of 2008, equivalent to an annual rate approaching half of that reached in 2006 when there were no charges to authors and the journal was using the previous longer format. For full information on the open-access mechanism, including available discounts, see the journal web site at http://journals.iucr.org/e/, where links can also be found to the updated Notes for Authors and other information and services for authors and readers. These include the free software publCIF, which provides excellent and easy-to-use facilities for turning a raw CIF from a refinement program into a suitable submission for the IUCr journals.

As a result of these changes, 2007 was a very challenging year, especially for the IUCr editorial staff in Chester, to whom we express our heartfelt thanks; we hope they will find 2008 a little easier as a result of their hard work. A continuing growth in manuscript submissions, and particularly the huge surge of papers submitted just before the change to open access, also put considerable strain on our team of Co-editors, and we are grateful to them for their extra efforts and patience, as well as to a number of Section $C$ Co-editors who accepted a shortterm extra allocation of papers from Section $E$ to spread this burden. Table 1 below illustrates well what a difficult time this was for all concerned. Indeed, the flood of submissions in November was so great that the decision had to be taken, reluctantly, to close the submission system for a few days near the end of the

Table 1

Papers submitted in each month of 2007.

\begin{tabular}{llllllllllll}
\hline Jan & Feb & Mar & Apr & May & Jun & Jul & Aug & Sep & Oct & Nov & Dec \\
\hline 458 & 350 & 681 & 445 & 521 & 518 & 487 & 465 & 450 & 785 & 1066 & 228 \\
\hline
\end{tabular}


month, as it was becoming impossible to handle all the submissions.

The total number of papers published in 2007 was 5181, compared with 3991 in 2006 and 2887 in 2005. Of these, $61 \%$ described organic, $36 \%$ metal-organic and $3 \%$ inorganic structures. $49 \%$ of papers had the main correspondence author in China, $8 \%$ in India, $6 \%$ in the USA, $5 \%$ in Germany, $4 \%$ in the UK, $3 \%$ in Malaysia, $3 \%$ in Turkey, and smaller percentages in other countries. $17 \%$ of submitted papers were withdrawn or rejected for various reasons. The journal's official impact factor stayed almost the same as the previous year, at 0.567 ; it will be interesting to see if there is a significant increase in this as a result of the potentially wider readership resulting from open access.

Professors S. Ohba and M. R. M. da Silva retired as Co-editors during the last year, and we thank them for their service to the journal. The current year will bring some significant changes in personnel. Both the founding Section Editors will be retiring from this role at the International Crystallography Congress in Osaka in August, and the task of appointing successors is currently underway. We expect that there may also be a small number of changes to the Co-editorial board; details will be given in a future editorial.

Among the most common changes made by Coeditors and Section Editors in the handling of manuscripts and proofs are corrections to references for computer software used in the control of diffractometers, data processing, structure solution and refinement, and the production of graphics and publication material. For many of the most commonly used programs there are standard references, either to a description in a published journal article or to a program writer or distributor; in some cases, citation of the standard reference in publications is a condition of use of the software. For convenience we provide below a list of standard references for many of these programs, which should generally be used in submissions to this journal. These will be incorporated in publCIF so that they may be readily inserted by users of that program in preparing a CIF for publication. Note that version numbers should not be given for programs. Alternative addresses of regional offices of commercial firms may also be given instead of those provided below. The list is not exhaustive.

\section{ABSCOR:}

Higashi, T. (1995). ABSCOR. Rigaku Corporation, Tokyo, Japan.

\section{APEX, APEX2, SMART, SAINT, SAINT-Plus:}

Bruker (2007). Program name(s). Bruker AXS Inc., Madison, Wisconsin, USA. [Older versions (pre-1997) should refer to Siemens Analytical X-ray Instruments Inc. instead of Bruker AXS.]

\section{CAD-4 Software:}

Enraf-Nonius (1989). CAD-4 Software (or CAD-4 EXPRESS). EnrafNonius, Delft, The Netherlands.

Cambridge Structural Database:

Allen, F. R. (2002). Acta Cryst. B58, 380-388.

\section{CAMERON:}

Watkin, D. J., Prout, C. K. \& Pearce, L. J. (1996). CAMERON. Chemical Crystallography Laboratory, Oxford, England.

CrysAlis CCD, CrysAlis RED and associated programs: Oxford Diffraction (2006). Program name(s). Oxford Diffraction Ltd, Abingdon, England.

\section{CRYSTALS:}

Betteridge, P. W., Carruthers, J. R., Cooper, R. I., Prout, K. \& Watkin, D. J. (2003). J. Appl. Cryst. 36, 1487.

\section{COLLECT:}

Nonius [or Hooft, R. W. W.] (1998). COLLECT. Nonius BV, Delft, The Netherlands.

\section{DENZO/SCALEPACK:}

Otwinowski, Z. \& Minor, W. (1997). Methods in Enzymology, Vol. 276, Macromolecular Crystallography, Part A, edited by C. W. Carter Jr \& R. M. Sweet, pp. 307-326. New York: Academic Press.

\section{DIAMOND:}

Brandenburg, K. [or Brandenburg, K. \& Putz, H., or Brandenburg, K. \& Berndt, M.] (1999). DIAMOND. Crystal Impact GbR, Bonn, Germany.

\section{DIF4 and REDU4:}

Stoe \& Cie (1991). Program name(s). Stoe \& Cie, Darmstadt, Germany.

DIRAX:

Duisenberg, A. J. M. (1992). J. Appl. Cryst. 25, 92-96.

\section{enCIFer:}

Allen, F. H., Johnson, O., Shields, G. P., Smith, B. R. \& Towler, M. (2004). J. Appl. Cryst. 37, 335-338.

\section{EVALCCD:}

Duisenberg, A. J. M., Kroon-Batenburg, L. M. J. \& Schreurs, A. M. M. (2003). J. Appl. Cryst. 36, 220-229.

\section{JANA2000:}

Petřıček, V. \& Dušek, M. (2000). JANA2000. Institute of Physics, Czech Academy of Sciences, Prague, Czech Republic.

\section{Mercury:}

Macrae, C. F., Edgington, P. R., McCabe, P., Pidcock, E., Shields, G. P., Taylor, R., Towler, M. \& van de Streek, J. (2006). J. Appl. Cryst. 39, 453-457.

\section{Mogul:}

Bruno, I. J., Cole, J. C., Kessler, M., Luo, J., Motherwell, W. D. S., Purkis, L. H., Smith, B. R., Taylor, R., Cooper, R. I., Harris, S. E. \& Orpen, A. G. (2004). J. Chem. Inf. Comput. Sci. 44, 2133-2144.

\section{ORTEPII:}

Johnson, C. K. (1976). ORTEPII. Report ORNL-5138. Oak Ridge National Laboratory, Tennessee, USA.

ORTEPIII:

Burnett, M. N. \& Johnson, C. K. (1996). ORTEPIII. Report ORNL6895. Oak Ridge National Laboratory, Tennessee, USA.

ORTEP-3:

Farrugia, L. J. (1997). J. Appl. Cryst. 30, 565. 


\section{PARST:}

Nardelli, M. (1995). J. Appl. Cryst. 28, 659.

\section{PLATON:}

Spek, A. L. (2003). J. Appl. Cryst. 36, 7-13.

\section{PROCESS:}

Rigaku (1996). PROCESS. Rigaku Corporation, Tokyo, Japan.

\section{PROCESS-AUTO:}

Rigaku (1998). PROCESS-AUTO. Rigaku Corporation, Tokyo, Japan.

\section{publCIF:}

Westrip, S. P. (2008). publCIF. In preparation.

\section{$S A D A B S, T W I N A B S$ :}

Bruker (2001). Program name. Bruker AXS Inc., Madison, Wisconsin, USA.

or

Sheldrick, G. M. (1996). Program name. University of Göttingen, Germany.

All programs beginning with SHELX:

Sheldrick, G. M. (2008). Acta Cryst. A64, 112-122.

SIR92:

Altomare, A., Cascarano, G., Giacovazzo, C., Guagliardi, A., Burla, M. C., Polidori, G. \& Camalli, M. (1994). J. Appl. Cryst. 27, 435.
SIR97:

Altomare, A., Burla, M. C., Camalli, M., Cascarano, G. L., Giacovazzo, C., Guagliardi, A., Moliterni, A. G. G., Polidori, G. \& Spagna, R. (1999). J. Appl. Cryst. 32, 115-119.

\section{SIR2002:}

Burla, M. C., Camalli, M., Carrozzini, B., Cascarano, G. L., Giacovazzo, C., Polidori, G. \& Spagna, R. (2003). J. Appl. Cryst. 36, 1103.

\section{TEXSAN:}

Molecular Structure Corporation \& Rigaku (2000). TEXSAN. MSC, The Woodlands, Texas, USA, and Rigaku Corporation, Tokyo, Japan.

\section{Win $G X$ :}

Farrugia, L. J. (1999). J. Appl. Cryst. 32, 837-838.

$X$-AREA, X-RED, X-RED32, X-SHAPE:

Stoe \& Cie (2002). Program name(s). Stoe \& Cie, Darmstadt, Germany.

$X C A D 4:$

Harms, K. \& Wocadlo, S. (1995). XCAD4. University of Marburg, Germany.

XSCANS:

Siemens (1994). XSCANS. Siemens Analytical X-ray Instruments Inc., Madison, Wisconsin, USA.

$X$-SEED:

Barbour, L. J. (2001). J. Supramol. Chem. 1, 189-191. 